\title{
Dicas para reconstrução artroscópica do cruzado anterior sem o garrote*
}

\section{Tips for Arthroscopic Anterior Cruciate Reconstruction without the Tourniquet}

\author{
Iberê Pereira Datti ${ }^{10}$ \\ ${ }^{1}$ Grupo de Cirurgia de Joelho, Clínica de Ortopedia e Traumatologia, \\ Hospital do Servidor Público Municipal, Aclimação, São Paulo, SP, \\ Brasil \\ Endereço para correspondência Iberê Pereira Datti, MD, Hospital do \\ Servidor Público Municipal, Rua Castro Alves, 60, Aclimação, São \\ Paulo, SP, 01532-000, Brasil (e-mail: iberedatti@hotmail.com).
}

Rev Bras Ortop 2021;56(2):256-257.

\section{Resumo}

Palavras-chave

- reconstrução do ligamento cruzado anterior

- torniquetes

- lesões do ligamento cruzado anterior
A reconstrução artroscópica do ligamento cruzado anterior é uma cirurgia comum realizada pelos cirurgiões ortopédicos dispostos a restaurar a estabilidade do joelho de pacientes fisicamente ativos. Apesar de ser geralmente um procedimento sem intercorrências, os cirurgiões devem sempre procurar melhores resultados pós-operatórios; neste cenário, a reconstrução artroscópica do ligamento anterior sem torniquete é uma alternativa promissora. O objetivo deste artigo é compartilhar com outros cirurgiões ortopédicos ao redor do mundo nossa experiência com este procedimento e algumas dicas técnicas que podem ser úteis.

The arthroscopic reconstruction of the anterior cruciate ligament is a common surgery performed by the orthopedic surgeons willing to restore the knee stability of physically active patients. Despite the fact that it is usually an uneventful procedure, surgeons must always look for better postoperative results; in this scenario, the arthroscopic reconstruction of the anterior cruciate ligament without a tourniquet is a promising alternative. The aim of the present paper is to share with other orthopedic surgeons around the world our experience with this procedure and some technical tips that may be helpful.

\section{Introdução}

A reconstrução artroscópica do ligamento cruzado anterior (RALCA) é uma das cirurgias ortopédicas mais realizadas. Nos

\footnotetext{
Trabalho realizado no Hospital do Servidor Público Municipal, Aclimação, São Paulo, SP, Brasil.
}

recebido

14 de Agosto de 2020

aceito

17 de Setembro de 2020
DOI https://doi.org/

$10.1055 / \mathrm{s}-0040-1722583$.

ISSN $0102-3616$
Estados Unidos, a incidência de RALCA é estimada em mais de $130 \mathrm{mil}^{1}{ }^{1}$ podendo chegar a mais de $400 \mathrm{mil} \mathrm{em}$ todo o mundo.

Os principais objetivos da RALCA são restaurar a estabilidade do joelho e permitir que os pacientes retornem sem restrições às atividades esportivas e cotidianas. Alcançar esses objetivos com menos complicações deve ser um esforço de todos os cirurgiões ortopédicos.
(C) 2021. Sociedade Brasileira de Ortopedia e Traumatologia. All rights reserved.

This is an open access article published by Thieme under the terms of the Creative Commons Attribution-NonDerivative-NonCommercial-License, permitting copying and reproduction so long as the original work is given appropriate credit. Contents may not be used for commercial purposes, or adapted, remixed, transformed or built upon. (https://creativecommons.org/ licenses/by-nc-nd/4.0/)

Thieme Revinter Publicações Ltda., Rua do Matoso 170, Rio de Janeiro, RJ, CEP 20270-135, Brazil 
Recentemente, a RALCA sem torniquete se tornou uma tendência emergente em todo o mundo, uma vez que o tempo cirúrgico não parece aumentar, ${ }^{2,3}$ e os pacientes parecem se sair melhor nas primeiras semanas pós-operatórias. ${ }^{4,5}$ Os supostos benefícios da reconstrução sem torniquete são a recuperação da força do quadríceps mais cedo, menor atrofia de circunferência de coxa, diminuição da perda de sangue, ${ }^{2}$ menos dores pós-operatórias, ${ }^{6}$ e menos alterações eletromiográficas. ${ }^{5} \mathrm{O}$ uso de torniquete também foi associado à paralisia pós-operatória dos nervos tibial, femoral e safeno. ${ }^{7,8}$

Nos últimos anos, devido às dificuldades logísticas de se ter um bom torniquete disponível em um hospital público de um país em desenvolvimento, nossa equipe realizou algumas RALCAs sem torniquete. Nossa experiência anedótica é semelhante à experiência de alguns outros grupos: pacientes submetidos a RALCA sem torniquete evoluem melhor do que os submetidos a RALCA com torniquete.

Apesar dos benefícios potenciais da RALCA sem torniquete, o perioperatório pode ser complicado devido à hemorragia intra-articular, especialmente depois de perfurar os túneis ósseos. O sangue torna quase impossível para o cirurgião identificar a estrutura nos primeiros minutos, e, para aqueles que não estão preparados para este cenário, a cirurgia pode se tornar uma tortura. É nossa intenção com este artigo compartilhar algumas dicas adquiridas com a experiência forçada que tivemos, de modo que talvez em um futuro próximo testes estudos comparando RALCA com e sem garrote possam ajudar o cirurgião ortopédico na decisão clínica.

\section{Técnica Cirúrgica}

Nossas dicas são:

- Comece tentando com um torniquete desinsuflado; sempre que você se sentir desconfortável, infle o torniquete e siga em frente.

- Ao colher o autoenxerto dos tendões isquiotibiais, certifique-se de cortar todas as vínculas e dividir o semitendinoso e o grácil da fáscia do sartório antes de usar o tenótomo.

- Mantenha-se longe da gordura do Hoffa o máximo possível. O portal anterolateral deve ser feito alto e próximo ao tendão patelar; o portal anteromedial deve ser feito um pouco mais medial do que o habitual.

- Seja paciente. O cirurgião deve manter a calma nos primeiros minutos de sangramento. Vai melhorar.

- Aumento da pressão e do fluxo na bomba de soro fisiológico. Se você não usar uma bomba, coloque a bolsa de soro fisiológico o mais alto possível.

- Soro fisiológico gelado também é uma boa opção para diminuir o sangramento.

- O ácido tranexâmico endovenoso (1 g) pode ser útil.

- Prefira ressecar o ligamento mucoso ao invés de ressecar a gordura de Hoffa.
- A adrenalina a $1 \mathrm{mg}$ para cada $1 \mathrm{~L}$ de soro fisiológico pode ser útil, principalmente nos primeiros minutos. Se necessário, $1 \mathrm{mg}$ de adrenalina diretamente na articulação definitivamente vai ajudar.

- Comece com as etapas artroscópicas que não precisam de raspagem da sinovia: inspeção e lesões meniscais.

- Evite a raspagem óssea desnecessária ou a curetagem óssea.

- Coloque os pinos-guia tibial e femoral no local desejado antes de perfurar os túneis ósseos.

- Se você escolheu uma técnica femoral de forapara dentro, tente não abrir a cápsula com o bisturi.

- Se você escolheu uma técnica transportal, comece com o pino-guia tibial antes de flexionar o joelho para colocar o pino-guia femoral.

- Comece sempre perfurarando o túnel femoral.

\section{Considerações Finais}

Apesar de a maioria dos cirurgiões não se sentirem confortáveis com a RALCA sem um torniquete, ela é um procedimento viável e seguro que tem potenciais benefícios em curto prazo para os pacientes. Seguindo essas dicas técnicas elementares, certamente a cirurgia será facilitada, e os cirurgiões se tornarão mais confiantes para abandonar 0 uso do torniquete.

Conflito de Interesses

Os autores declaram não haver conflito de interesses.

\section{Referências}

1 Mall NA, Chalmers PN, Moric M, et al. Incidence and trends of anterior cruciate ligament reconstruction in the United States. Am J Sports Med 2014;42(10):2363-2370

2 Kuo LT, Yu PA, Chen CL, Hsu WH, Chi CC. Tourniquet use in arthroscopic anterior cruciate ligament reconstruction: a systematic review and meta-analysis of randomised controlled trials. BMC Musculoskelet Disord 2017;18(01):358-358

$3 \mathrm{Wu} \mathrm{H}$, Chen LX, Li YL, et al. Tourniquet used in anterior cruciate ligament reconstruction: a system review. Eur J Orthop Surg Traumatol 2014;24(06):999-1003

4 Daniel DM, Lumkong G, Stone ML, Pedowitz RA. Effects of tourniquet use in anterior cruciate ligament reconstruction. Arthroscopy 1995;11(03):307-311

5 Arciero RA, Scoville CR, Hayda RA, Snyder RJ. The effect of tourniquet use in anterior cruciate ligament reconstruction. A prospective, randomized study. Am J Sports Med 1996;24 (06):758-764

6 Reda W, ElGuindy AMF, Zahry G, Faggal MS, Karim MA. Anterior cruciate ligament reconstruction; is a tourniquet necessary? A randomized controlled trial. Knee Surg Sports Traumatol Arthrosc 2016;24(09):2948-2952

7 Guanche CA. Tourniquet-induced tibial nerve palsy complicating anterior cruciate ligament reconstruction. Arthroscopy 1995;11 (05):620-622

8 Kornbluth ID, Freedman MK, Sher L, Frederick RW. Femoral, saphenous nerve palsy after tourniquet use: a case report. Arch Phys Med Rehabil 2003;84(06):909-911 